\title{
Diários reflexivos e avaliação formativa: um olhar sobre a prática do professor
}

Reflexive diaries and formative assessment: a view on the teacher's practice

Márcia Aparecida Silva*

\begin{abstract}
RESUMO: Neste artigo, que é um recorte de minha dissertação de mestrado, pretendo discorrer sobre a escrita de diários reflexivos e a avaliação formativa na prática pedagógica do professor. Tenho interesse em saber de que forma a professora reflete sobre sua prática ao escrever os diários. Para nortear a pesquisa, baseio-me em Liberali, (1999), Soares (2006), Felice (2005), Fidalgo (2002), entre outros pesquisadores. Esse trabalho se configura como um estudo de caso porque a pesquisa ocorreu em duas aulas de nono ano em que fui professora de inglês em 2012. As análises revelam que a escrita de diários possibilitou reflexões sobre a prática pedagógica da professora, o que demandou mudanças dessas práticas.
\end{abstract}

PALAVRAS-CHAVE: Linguística Aplicada. Diário reflexivo. Língua inglesa.

\begin{abstract}
In this article, which is part of my dissertation, I aim to discuss about the writing of reflexive diaries and formative assessment in the teacher pedagogical practice. I want to research how teachers reflect on his or her practice while writing the diaries. To guide the research, I based on Liberali, (1999), Soares (2006), Felice (2005), Fidalgo (2002), among other researchers. This article is inserted in Case Study modality based on Stake (1995) because the research took place in two classes of ninth grade where I was an English teacher in 2012. The analysis show that the writing of the diaries allowed reflections about the teacher pedagogical practice, what demanded changing of these practices.

KEYWORDS: Applied Linguistics. Reflexive diaries. English language.
\end{abstract}

\section{Introdução}

O trabalho com a escrita de diários no ensino fundamental foi algo que me encantou desde o primeiro momento, e meu interesse em pesquisar o uso de tal ferramenta se iniciou quando comecei a trabalhar em uma escola estadual da rede pública da cidade de UberlândiaMG.

Cada dia em que ministrei aulas nessa escola para turmas do sexto e nono do ensino fundamental foi único, cada aula uma experiência diferente do que eu estava habituada. Ao mesmo tempo em que trabalhava nessa escola pública, participava de uma disciplina no curso de mestrado, cujo foco se baseava em discussões relacionadas à avaliação no âmbito escolar. Na disciplina, nós sempre discutíamos sobre avaliação com intuito de refletir sobre o papel da

\footnotetext{
${ }^{*}$ Mestre em Linguística pelo PPGEL/UFU.
} 
avaliação nas escolas, não apenas como produto final, mas como parte do processo de aprendizagem dos alunos.

Além dos alunos, nessa disciplina discutíamos sobre a reflexão que a escrita de diários poderia proporcionar para a prática pedagógica do professor. Assim, decidi realizar uma pesquisa que discutisse a escrita de diários em sala de aula como forma de reflexão e avaliação tanto para os alunos quanto para o professor.

Neste artigo, optei por não trazer exemplos dos os diários dos alunos, visto que a ênfase será dada às contribuições da escrita dos diários para a transformação da prática do professor. Para tanto, a seguinte pergunta de pesquisa foi elencada: como escrever o diário reflexivo pode colaborar para com a mudança da prática pedagógica da professora?

$\mathrm{Na}$ primeira parte do artigo, discuto a escrita de diários reflexivos, resenhando alguns trabalhos na área; logo após, descrevo a metodologia utilizada. $\mathrm{Na}$ seção de análise, trago excertos dos diários da professora em que seja possível perceber como o diário faz com que ela reflita sobre suas aulas e sua formação acadêmica.

Passo, a seguir, à discussão teórica do artigo.

\section{Escrita de diários reflexivos}

A escrita de diários sejam eles íntimos, reflexivos, de leitura, de aprendizagem, sempre nos levam a refletir sobre determinado ponto. De modo geral, no ambiente acadêmico, o diário é utilizado para colaborar com a aprendizagem dos alunos. Contudo, não são apenas os alunos os beneficiários, o professor também se beneficia dessa escrita, pois ele lê o que os alunos estão escrevendo e, em sua leitura, ele reflete sobre sua prática em sala de aula.

Como a escrita de diários é profícua, vários estudos têm sido realizados com o intuito de entender e explorar essa ferramenta. Em sua pesquisa, Soares (2006) analisou quatorze diários reflexivos escritos por nove alunos, em uma disciplina de língua inglesa, do primeiro ano de um curso de Letras Inglês. Seu interesse foi perceber de que modo a identidade desses alunos seria percebida por meio da escrita dos diários.

O conceito de diário para a referida pesquisa foi baseado em Liberali (1999) e Machado (1998). Para definição do termo, Soares (2006) relaciona a escrita do diário reflexivo com a escrita do diário íntimo. Apesar de compreender as especificidades dos diários, como, por exemplo, o seu lugar social e a finalidade da escrita, Soares (2006) argumenta que há um traço comum nos diários: ambos escrevem para um interlocutor, o diário íntimo é uma escrita para si 
e o diário reflexivo está na fronteira entre o discurso para si e o discurso para o outro. (SOARES, 2006, p. 56).

É possível notar, a partir dos diários analisados por Soares (2006), que os alunos conseguiram refletir sobre sua aprendizagem, se posicionando em relação a aspectos que julgavam mais importantes. Além disso, reviram posicionamentos que poderiam prejudicar a aprendizagem, tais como a necessidade de ter tarefa de casa e participação nas atividades em sala. Os diários foram analisados separadamente por aluno, assim, a pesquisadora pôde perceber a construção das identidades que emergiram dos diários. Para Soares (2005, p. 85), os diários podem revelar a relação do aluno com o conteúdo, com o professor ou outros colegas, com a metodologia, com experiências anteriores.

Em outra pesquisa sobre a temática, Soares (2005), ao utilizar o diário reflexivo para a aprendizagem da língua inglesa, percebeu que a escrita em diários possibilita uma maior interação na relação professor-aluno, o diário seria então um espaço legítimo no qual o aluno pode expressar, com sua própria voz, suas percepções e sentimentos sobre a vida na escola, [com] reflexões a partir de experiências concretas (SOARES, 2005, p. 80).

A pesquisa de Soares (2006) revela o quanto o diário pode ser visto como um instrumento eficaz para a interação professor aluno. Apesar de não ter sido foco da pesquisadora, em vários momentos, ela mencionou que os alunos dialogavam com a professora por meio do diário, seja para expor o ponto de vista acerca de certos procedimentos, seja para elogiar. A questão da reflexão também aparece nos resultados de Soares (2006), os alunos, à medida que escreviam, conscientizavam-se de aspectos importantes para a aprendizagem, como fazer as tarefas de casa.

Sobre o conceito de diário reflexivo, tal como Soares (2006), busquei no trabalho de Liberali (1999) o suporte necessário para minha pesquisa. Liberali (1999) pesquisou como a reflexão ocorreu em vinte e três diários de cinco alunas em um curso ministrado por ela. A autora se embasou teoricamente na perspectiva de Smith (1992), sobre reflexão técnica, prática e crítica para discutir sobre o conceito de reflexão.

De acordo com Liberali (1999), ao escrever em um diário, o aluno acaba por refletir criticamente sobre todo o processo de aprendizagem, tornando-se mais independente, podendo buscar outros meios, tais como seu conhecimento de mundo, que facilitem seu entendimento.

Ao concluir seu trabalho, Liberali (1999, p. 140) argumentou que, em apresentações feitas por alunos professores em um congresso, sobre o uso de diários, parece ficar evidente 
que alguns aspectos que não pareciam ter muita importância, ao serem descritos $e$ "informados" assumem relevância e passam a despertar novos questionamentos. Esse aspecto do diário reflexivo é importante na medida em que, ao escrever sobre suas impressões, o aluno reflete sobre pontos que, talvez, em outros momentos, não lhe interessariam.

Além disso, o aluno, ao escrever o diário, tem uma liberdade de expressão maior do que teria se, em vez de escrever, houvesse uma discussão em sala de aula com o professor e os colegas, por exemplo. Ao escrever pensando em apenas um leitor específico, o aluno pode sentir-se mais confiante em sua reflexão, pode avaliar suas práticas sem medo de sentir-se exposto diante dos colegas, uma vez que apenas o professor tomará conhecimento do conteúdo de sua escrita.

No âmbito escolar, acredito que a reflexão precisa ser entendida como um processo que permeia (ou, pelo menos, deveria permear) quase todas as ações do professor. É a partir da reflexão sobre sua prática pedagógica que o professor e os alunos podem olhar criticamente para o processo de ensino e aprendizagem nos quais estão inseridos, tentando pensar em outras possibilidades de ensinar, aprender e até mesmo avaliar.

O termo reflexão tem sido estudado por diversos pesquisadores no âmbito da Linguística Aplicada, tais como Reis (2007), Ghedin (2008), Liberali (1999), Soares (2005, 2006), Machado (1998), dentre outros. Um dos objetivos dessas pesquisas é colaborar para que o professor repense suas práticas, avaliando o que precisa ser modificado em sala de aula. Além do professor, os alunos também se beneficiam do uso do diário porque, a partir da escrita, refletem e avaliam seu próprio processo de aprendizagem.

Cunha (1986, p. 670) define o termo reflexão como fazer retroceder, desviando da direção inicial; espelhar, revelar, pensar. Seguindo os significados etimológicos dados por este autor, a reflexão tem espaço na sala de aula, pois permite que aluno e professor retrocedam e repensem suas práticas, tentando outros caminhos possíveis para a aprendizagem.

Para Ghedin (2008), a reflexão é uma espécie de mola que impulsiona a mudança. O autor argumenta que

Pensar a reflexão como caminho exige-se um ato de vontade e um ato de coragem gerador e impulsionador de mudança. Todos os limites impostos à reflexão não são mais que portas abertas em direções que ainda não havíamos percebido. Tal apologia da reflexão tem por suporte a mais firme razão de que sem ela não podemos ter acesso ao ser da humanidade. É nesta, e só por esta razão, que o processo reflexivo-crítico se sustenta no horizonte da educação, como um meio para que o humano se torne possível. (GHEDIN, 2008, p. 148). 
Percebe-se que é por meio da reflexão que mudanças são possíveis; seria esse processo reflexivo-crítico que possibilitaria que professores e alunos revissem suas práticas pedagógicas. Além disso, observa-se que a relação entre reflexão e experiência é bem próxima; a reflexão surgiria e seria melhor entendida por intermédio da experiência. A reflexão pode ser concebida aqui como uma avaliação da experiência já ocorrida.

Assim, a experiência pode ser relacionada à reflexão, pois pode ser entendida tanto em um contexto social quanto pessoal (DEWEY, 2011, [1938]). Segundo a teoria proposta por Dewey (2011, [1938], p. 29), totalmente independente do desejo ou da intenção, toda experiência vive e se perpetua nas experiências que a sucedem. Com isso, é a partir das experiências vividas e refletidas que outras possibilidades podem ser pensadas. A escrita de diários sobre a experiência vivida em sala de aula tem relevância para a presente pesquisa, pois pode constituir um valioso instrumento para promover uma reflexão pessoal do aluno acerca do seu processo de aprendizagem (REIS, 2007, 24).

Ainda na busca de definições para um termo tão complexo, recorro a Liberali (1999) que, em seus estudos da obra de Van Manen (1977), discorre sobre três formas de reflexão, a saber: técnica, prática e crítica.

A primeira é relacionada ao conhecimento técnico, não havendo nessa reflexão um desejo de mudança. Seu objetivo é refletir sobre os meios para se chegar a determinado fim. De acordo com Liberali (1999, p. 25), há o interesse por aquele tipo de conhecimento que permite a previsão e controle dos eventos.

A segunda definição, chamada de reflexão prática, como o próprio nome já indica, é voltada para fins práticos, cujo intuito é problematizar os resultados encontrados a partir de determinada ação. Pode-se afirmar que há, nesse tipo de reflexão, uma tentativa de promover dado entendimento sobre o conhecimento.

A terceira e última definição discutida por Liberali (1999), a crítica, seria uma proposta de reflexão sobre a ação, no sentido de reconstruí-la, e também, abarcaria as reflexões técnica e prática. O objetivo deste tipo de reflexão é tentar buscar respostas para problemas ocorridos nos outros modelos de reflexões e que possibilitaria uma maior autonomia dos indivíduos envolvidos na ação.

Dessa forma, a reflexão crítica é relevante, uma vez que os alunos, ao escreverem e compartilharem comigo os diários refletindo sobre as aulas, refletem também sobre suas ações, o que pode colaborar com o processo de aprendizagem, no sentido de que possibilita possíveis 
reconstruções de práticas. Ressalto que o contexto da pesquisa de Liberali (1999), uma sala de aula do curso de graduação, influenciou na reflexão que os alunos construíram. Isso porque os alunos eram mais maduros, mais cientes de seu papel no processo de aprendizagem.

Assim, apesar de basear-me teoricamente em Liberali (1999) sobre a questão da reflexão, entendo que o contexto em que minha pesquisa ocorreu, uma sala de aula do ensino fundamental, pode influenciar a reflexão dos alunos e mesmo as tomadas de posição após refletirem sobre as aulas.

Tal fato ocorre devido ao nível de maturidade dos alunos, o que influenciaria na reconstrução dessas práticas pedagógicas. Por essa razão, acredito que, a depender do contexto escolar, a reflexão pode não ser sinônimo de mudança ou reconstrução de práticas.

Para Pimenta e Ghedin (2008), o conceito teórico de reflexão refere-se ao estudo de teorias que permitam, de certo modo, entender as práticas pedagógicas do professor e dos alunos, colaborando com o processo de ensino e aprendizagem escolares.

Dessa maneira, pensando na escrita de diários como uma prática reflexiva, concordo com Zabalza (2004, p. 44) quando esse argumenta que:

A reflexão como dimensão constitutiva dos diários é o segundo grande aspecto a ser destacado. Basicamente toda minha concepção de didática está montada sobre o princípio da reflexão e o que isso implica por considerar o professor e os alunos como agentes conscientes do processo de ensino.

É possível pensar, então, que a reflexão colabora para com a aprendizagem dos alunos, assim como com a prática pedagógica do professor. Entendo aqui, ancorada nos estudos de Liberali (1999), que refletir pode implicar em mudança de práticas, a depender de outros fatores e, talvez, essas mudanças possam ajudar na aprendizagem.

Passo, agora, a descrever a metodologia.

\section{Metodologia}

A metodologia escolhida para esse artigo é o estudo de caso. Tal escolha se justifica por tratar-se de um estudo de minha própria experiência profissional, como professora de língua inglesa, em trabalhar com diários reflexivos em salas de aula do nono ano de uma escola pública de ensino, por um período de tempo determinado. Segundo Telles (2002, p. 108), “os estudos de caso, frequentemente descritivos (mas, também, podendo ser narrativos), são utilizados quando o professor-pesquisador deseja enfocar um determinado evento pedagógico, componente ou fenômeno relativo à sua prática profissional”. 
É possível notar que os estudos de casos podem fornecer alto teor interpretativista. Segundo Coelho (2005, p. 47), "os dados em um estudo de caso podem ser obtidos através de instrumentos de coletas mais propícias para a pesquisa qualitativa". A metodologia que envolve os estudos de casos pode ser compreendida de diversas formas. Mobilizo, neste artigo, os estudos de Stake (1995), que distingue três formas distintas de se entender o estudo de caso, a saber: o estudo intrínseco, o coletivo e o instrumental.

A primeira forma se refere a um estudo específico de caso, que pode ser entendido como um estudo mais elaborado sobre um problema ou uma temática que surge em sala de aula e que nos impulsiona a tentar resolvê-lo, ou mesmo quando decidimos avaliar determinados procedimentos ocorridos em sala de aula.

A segunda forma, coletiva, refere-se a estudos realizados em um prazo mais longo, podendo ser entendido como um estudo de casos coletivos. Aqui, as pesquisas envolvem vários casos que podem ou não ser similares, e que podem levar à compreensão de determinado problema de forma mais ampla.

A terceira e última forma proposta por Stake (1995), chamada de instrumental, referese a estudos de caso particulares que são realizados com o intuito de observar a aplicabilidade de determinada teoria. A presente pesquisa se assemelha ao primeiro modelo proposto por Stake (1995), pois, a pesquisa se iniciou a partir de meu interesse em observar como a escrita de diários reflexivos poderia contribuir para as práticas de sala de aula.

O contexto em que a pesquisa ocorreu se refere a duas salas de aula do nono ano do ensino fundamental, nas quais ministrei aulas de língua inglesa como professora designada durante um semestre no ano de 2012. Tal escola pertence à rede pública estadual de ensino de Uberlândia-MG. A escola em questão possui vinte e sete salas de aulas com uma média de 39 alunos por sala e funciona nos períodos da manhã e da tarde. As séries do quinto $\left(5^{\circ}\right)$ ao nono $\left(9^{\circ}\right)$ ano funcionam no turno matutino e as turmas do primeiro $\left(1^{\circ}\right)$ ao quarto $\left(4^{\circ}\right)$ ano no período da tarde.

Para coleta dos dados foram utilizados: notas de campo, descrição das aulas, planos de aula, livro didático, atividades dadas aos alunos e diários escritos pelos alunos e por mim, professora da turma, com os relatos das experiências que vivenciamos em sala de aula.

Com relação à escrita de diário reflexivos, há diversas vantagens em se utilizá-los como ferramenta de pesquisa, pois eles geralmente são ricos em dados tanto quantitativos quanto qualitativos; além disso, McDonough e McDonough (1997) argumentam que os alunos, ao 
escrever o diário, podem refletir sobre o que aconteceu em sala de aula, o que deveria ter acontecido, as mudanças ocorridas, como eles se sentiram sobre todos esse fatores. Enfim, os diários são uma fonte valiosa para pesquisa, pois podem possibilitar ao pesquisador mais dados sobre as práticas de sala de aula.

Como participante da pesquisa, eu escrevi cinco diários nos quais refleti sobre as aulas e minha relação com os alunos. Meus diários foram escritos após as aulas, apenas que apenas o primeiro foi escrito após minha leitura dos diários dos alunos, os outros escrevi sobre minha relação com eles nas aulas. Como professora de língua estrangeira, ministrei aulas em cursos de idiomas por mais ou menos quatro anos e em escolas de ensino regular por dois anos. Como sempre gostei bastante de ensinar línguas estrangeiras, sempre busquei formas que colaborassem com a aprendizagem dos alunos.

Como eu nunca havia tido contato com essa ferramenta antes, busquei saber se ela, de fato, poderia ser profícua para a aprendizagem de línguas estrangeiras, em especial, da língua inglesa.

Para uma melhor visualização do artigo, construí um quadro em que é possível visualizar a pergunta de pesquisa, o material utilizado, a justificativa para a pergunta e a base teórica para análise.

Quadro 1: Resumo da pergunta, fontes de dados e métodos, justificativa e base teórica da pesquisa

\begin{tabular}{|c|c|c|c|}
\hline $\begin{array}{l}\text { Pergunta de } \\
\text { pesquisa }\end{array}$ & $\begin{array}{l}\text { Fontes de dados e } \\
\text { métodos }\end{array}$ & Justificativa & Base teórica \\
\hline \begin{tabular}{lr} 
Como escrever & o \\
diário & \multicolumn{2}{c}{ pode } \\
colaborar com a \\
reflexão que o \\
professor constrói \\
sobre sua prática?
\end{tabular} & $\begin{array}{l}\checkmark \text { Diários escritos } \\
\text { pela professora } \\
\checkmark \text { Diários escritos } \\
\text { pelos alunos } \\
\checkmark \text { Notas de campo }\end{array}$ & $\begin{array}{l}\text { A escrita dos } \\
\text { diários pela } \\
\text { professora poderá } \\
\text { revelar de que } \\
\text { maneira ela reflete } \\
\text { sobre sua própria } \\
\text { prática pedagógica. }\end{array}$ & $\begin{array}{l}\text { Reflexão } \\
\text { Cf: } \\
\text { 1. Machado (1998) } \\
\text { 2. Liberali (1999) } \\
\text { Avaliação Formativa } \\
\text { Cf: } \\
\text { 1. Taras (2007) } \\
\text { 2. Lisboa (2007) }\end{array}$ \\
\hline
\end{tabular}

Para responder a pergunta de pesquisa: como escrever o diário pode colaborar com a reflexão que o professor constrói sobre sua prática?, elenco trechos dos diários escritos pela professora e alguns trechos dos diários dos alunos, quando necessário. A base teórica para discutir reflexão será composta por Machado (1998) e Liberali (1999), dentre outros. Para discutir avaliação formativa, baseio-me em Taras (2007) e Lisboa (2007). 
As análises tem como suporte teórico a concepção de avaliação proposta por Taras (2007), os quais discutem sobre avaliação somativa e formativa. Tais conceitos são importantes, pois, conforme já dito, os diários se inserem em uma proposta de avaliação que não contempla o somativo.

\section{Análise dos diários da professora}

Pretendo analisar excertos dos diários escritos por mim, professora participante, em que seja possível perceber a reflexão que a escrita de diários proporciona.

Quadro 2: Autoavaliação da professora

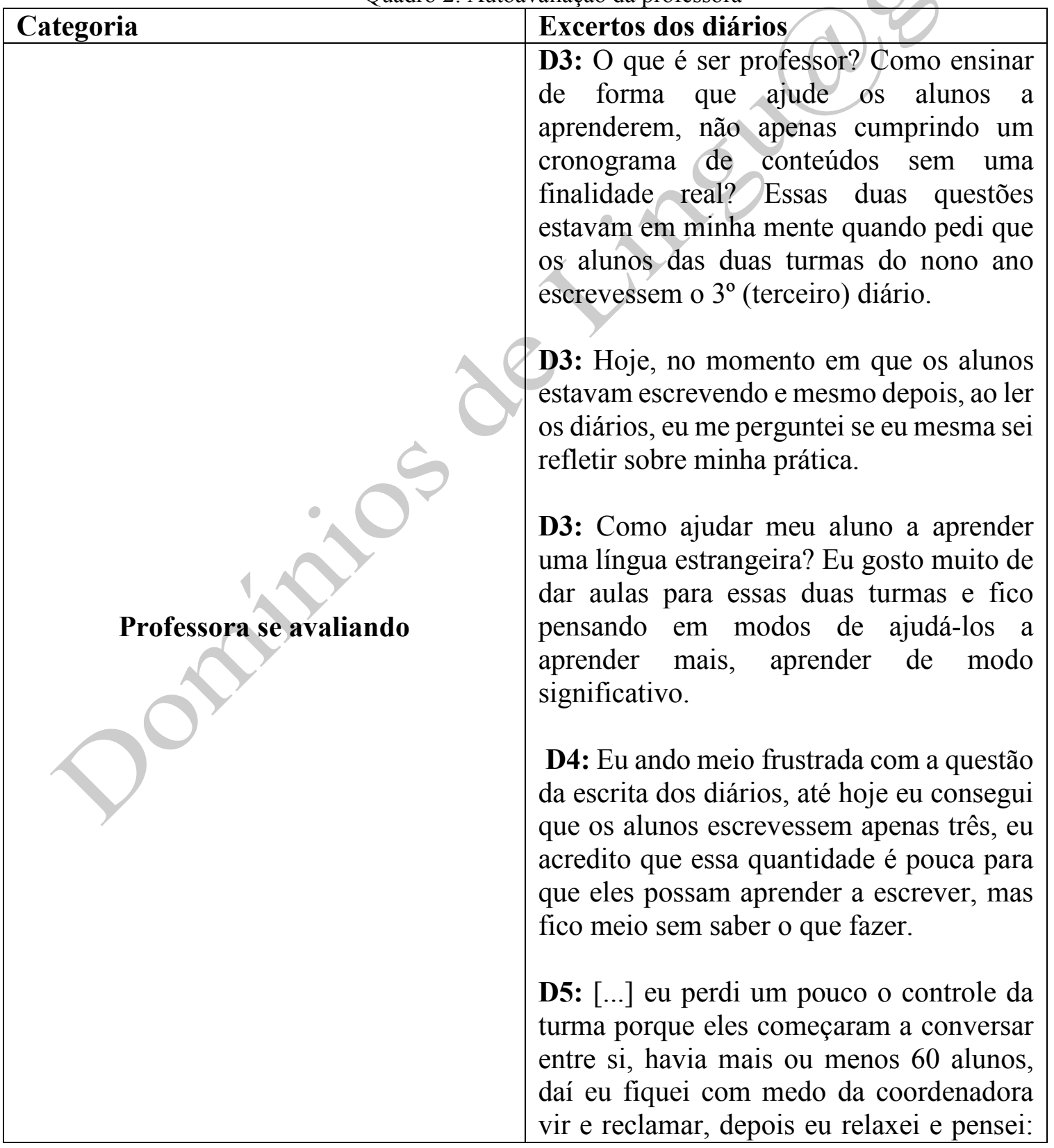




\begin{tabular}{|l|l|}
\hline & "que nada, esse é o momento dos alunos". \\
& Decidi deixá-los mais a vontade então. \\
\hline
\end{tabular}

Segundo Zabalza (2004, p. 44), “o próprio fato de escrever, de escrever sobre sua própria prática, leva o professor a aprender por sua narração. Ao narrar sua experiência recente não só a constrói linguisticamente como a reconstrói como discurso prático e como atividade profissional". Concordo com essa afirmação de Zabalza, de fato, o processo de escrita de diários colabora com as reflexões que o professor constrói sobre si mesmo.

O professor, ao escrever diários tem mais possibilidades de refletir sobre sua prática, o que é confirmado pelo primeiro excerto da professora selecionado para análise, no qual há um questionamento sobre o que seja ser professor. Nota-se que a professora avalia a necessidade que há, ao menos no contexto pesquisado, em se seguir o planejamento escolar.

A reflexão sobre a prática pedagógica da professora é observada no segundo e terceiro excertos mobilizados para esta análise, em que ela argumenta: "hoje, no momento em que os alunos estavam escrevendo e mesmo depois, ao ler os diários, eu me perguntei se eu mesma sei refletir sobre minha prática" (diário 3 da professora); e também quando se questiona: "Como ajudar meu aluno a aprender uma língua estrangeira?" (diário 3 da professora). Percebe-se aqui uma preocupação da professora com o uso da língua inglesa, ela não está preocupada em seguir uma agenda de conteúdos. Toda sua reflexão se pauta sobre sua prática pedagógica; talvez essa preocupação seja um reflexo da escrita dos diários dos alunos, em que afirmam, por vezes, que não aprenderam nada.

Tais excertos revelam que a escrita de diários funciona como ferramenta de reflexão também para o professor. Ao escrever sobre os alunos ou as aulas, o professor tem mais possibilidades de refletir sobre o contexto, o que talvez, em outros momentos, com outros instrumentos não fosse possível. Assim, "a reflexão é, portanto, um dos componentes fundamentais dos diários dos professores" (ZABALZA, 2004, p. 45).

No final do terceiro excerto, a professora afirma que reflete sobre formas de ensinar os alunos de modo significativo. Mas, o que seria significativo? E para quem seria significativo? Para ela ou para os alunos? Tal termo parece gerar uma inespecificidade. O termo modo parece sugerir a preocupação da professora com o método de ensino, o que sugere certo peso de sua constituição como professora de cursinhos de idiomas, lugares em que a questão do método é enfatizada. 
Ao escrever "mas fico sem saber o que fazer", no terceiro diário, a professora evidencia, uma vez mais, a reflexão constante sobre sua prática, que advém da relação estabelecida com os alunos. Pode-se pensar aqui em uma necessidade de controle: ela precisa saber o que fazer para controlar sua prática, o que reforça o argumento pautado anteriormente de que a professora se insere em uma prática de ensino tradicionalista, na qual o professor é o centro do processo de aprendizagem.

Em seu quarto diário, nota-se que a professora se identifica com a prática de escrita de diários, pois ela se preocupa com o andamento das aulas nesse sentido. Ao escrever o quarto diário, ela afirma que se sentia frustrada porque não conseguira que os alunos redigissem a quantidade de diários considerados necessários. Observa-se que ela parece estar presa ao aspecto quantitativo dos diários, sua preocupação estando no fato de que os alunos estariam escrevendo poucos diários, logo, não estariam aprendendo a escrever.

Conforme explicitado no capítulo metodológico, o foco inicial da pesquisa era na aprendizagem da escrita da língua inglesa, contudo, pelo tempo em que a pesquisa durou, não foi possível focar nesse aspecto. Logo, a preocupação da professora com a quantidade de diários pode ser uma consequência desse objetivo primeiro.

No quinto diário, nota-se que a professora ainda está arraigada a valores antigos como, por exemplo, a necessidade de controlar os alunos. Tal argumento é confirmado com o trecho:

[...] eu perdi um pouco o controle da turma porque eles começaram a conversar entre si, havia mais ou menos 60 alunos, daí eu fiquei com medo da coordenadora vir e reclamar, depois eu relaxei e pensei: "que nada, esse é o momento dos alunos". Decidi deixá-los mais a vontade então. (diário 5 da professora).

Ao descrever um acontecimento ocorrido durante a apresentação dos trabalhos dos alunos das duas turmas, a professora demonstra que, apesar de tentar se inserir em um paradigma dialógico de aprendizagem, em que o aluno se corresponsabiliza por sua aprendizagem e também avaliação, a professora parece, em um primeiro momento, não entender que é preciso dar liberdade e autonomia aos alunos, eles são capazes de encontrar seu próprio caminho.

A corresponsabilização dos alunos, neste caso específico, relaciona-se com o caráter relacional da interação (FIDALGO, 2006). Tal relação se torna possível, neste contexto, porque quando se entende que a avaliação possui um caráter relacional, abrem-se vias para a corresponsabilização do aluno no processo de aprendizagem. Além disso, ao se preocupar com 
a (in)disciplina dos alunos, a professora evidencia sua preocupação com sua prática pedagógica, uma vez que ela precisa lidar com o que foge ao controle.

Desse modo, nesta análise, o intuito foi mostrar excertos dos diários da professora em que fosse possível observar a autoavaliação. Conforme pode ser percebido, em sua maioria, a professora avalia suas práticas sempre em um contraponto com a vivência com os alunos ou pela escrita dos diários deles. É a partir das experiências de sala de aula, ou mesmo da escrita dos diários dos alunos, que a professora, por vezes, repensa sua conduta. Tal fato pode ser confirmado no quadro apresentado anteriormente mobilizado.

\section{Considerações finais}

A pergunta de pesquisa, a saber: como escrever o diário pode colaborar com a reflexão que o professor constrói sobre sua prática? teve como base os diários escritos por mim, professora da turma. Para responder a essa pergunta, mobilizei o conceito de avaliação formativa com base em Taras (2007), Lisboa (2007) e discuti também sobre reflexão me apoiando teoricamente em Machado (1998), Liberali (1999), dentre outros.

$\mathrm{O}$ padrão temático selecionado na escrita de seus diários refere-se à resistência em ensinar determinados conteúdo, tais como: vocabulário e tradução. Fica evidente a preocupação com sua prática pedagógica. Além disso, a professora não ouviu os alunos para planejar as aulas, deixando de lado o que eles queriam aprender.

Um ponto que o diário reflexivo possibilitou visualizar se refere à tensão que ocorreu entre o padrão temático da proféssora, uma vez que os alunos pediram determinados conteúdos que a professora resistiu em ministrar. Houve, aqui, um jogo de poder em que a professora se pauta no que julga ser pertinente ensinar, sem dar importância ao que os alunos estão pedindo nos diários, como o ensino de vocabulário. A professora assume uma postura tradicionalista, de detentora do saber, não levando em consideração o desejo dos alunos. Tal postura fica evidente a partir da prática pedagógica da professora.

A partir da análise dos dados foi possível notar que a professora reflete sobre suas práticas tendo como base sua relação com os alunos e os conteúdos dos diários deles. Pode-se argumentar que o diário contribui para a prática pedagógica da professora na medida em que ela, ao escrever, percebe fatos que antes não havia notado. Segundo Yinger e Clark (1981), ao escrever sobre determinado assunto pedagógico, há a possibilidade de se ter compreensão mais 
profunda das ações em sala de aula, o que poderia sugerir uma mudança possível nas práticas escolares.

A possível mudança de prática visível da professora nota-se no momento em que ela trabalha com vocabulário na escrita dos diários, algo que os alunos pediram e que ela resistiu por um bom tempo. O ensino de vocabulário só foi possível após a leitura dos diários dos alunos e escrita do diário da professora, isso porque eles optaram por escrever nos diários que queriam estudar vocabulário e, apesar da resistência em ensinar esse tópico, a professora decidiu encontrar um modo que trabalhá-lo. Pode-se notar aqui que reflexão implica mudança de prática pedagógica, conforme Liberali (1999).

Ressalto aqui que, apesar de professora trabalhar com o ensino de vocabulário, tal fato não implica uma mudança de prática significativa. Ela ainda parece se basear em uma postura tradicionalista. Segundo Fidalgo (2006), refletir nem sempre implica uma possível mudança de práticas. Com certeza a mudança se inicia com a reflexão, contudo, é preciso empenho por parte do professor para se desvincular de posturas tradicionalistas.

\section{Referências Bibliográficas}

COELHO, H.S.H. É possível aprender inglês na escola? crenças de professores e alunos sobre professores e alunos sobre o ensino de inglês em escolas públicas. Dissertação de mestrado. Universidade Federal de Minas Gerais, 2005.

CUNHA, A. G. Dicionário etimológico Nova Fronteira da língua portuguesa. $2^{\circ} \mathrm{ed}$. de Janeiro: Nova Fronteira, 1986.

DEWEY, J. Experiência e educação. 2º ed. Petrópolis, RJ: Vozes, 2011, [1938].

FELICE, M. I. V. A identidade de ingressantes no Ensino Superior por duas modalidades de processo seletivo: as perspectivas de professores e alunos. Tese de doutorado - Pontifícia Universidade Católica de São Paulo. Área de Concentração: Linguística Aplicada e Estudos da Linguagem. 2005.

FIDALGO, S. S. A avaliação de ensino-aprendizagem: ferramenta para a formação de agentes críticos. Dissertação de Mestrado em Linguística Aplicada e Estudos da Linguagem. Pontifícia Universidade Católica de São Paulo. 2002.

FIDALGO, S. S. A avaliação na escola: um histórico de exclusão social-escolar ou uma proposta sociocultural para a inclusão? In: Revista Brasileira de Linguística Aplicada, v. 6, n. 2. Belo Horizonte MG: Faculdade de Letras da UFMG. 2006, p. 15-31 
GHEDIN, E. Professor reflexivo: da alienação da técnica à autonomia da crítica. In: PIMENTA, S. G; GHEDIN, E. Professor reflexivo no Brasil: gênese e crítica de um conceito. 4 ed. São Paulo: Cortez, 2008.

LIBERALI, F. C. O diário como ferramenta para a reflexão crítica. Tese (Doutorado em Linguística Aplicada ao ensino de línguas). Pontifícia Universidade Católica de São Paulo. São Paulo. 1999.

MACHADO, A. R. O diário de leituras: a introdução de um novo instrumento na escola. São Paulo: Martins Fontes, 1998.

MCDONOUGH, L; MCDONOUGH, S. Research methods for English language teachers. Londres: Arnold, 1997.

PIMENTA, S. G \& GHEDIN, E. Professor reflexivo no Brasil: gênese e crítica de um conceito. 4 ed. São Paulo: Cortez, 2008.

REIS, V. S. O Diário de Aprendizagem de Língua Estrangeira (Inglês) sob a perspectiva do Processo Discursivo. Dissertação de Mestrado pela Universidade Federal de Minas Gerais. Programa de Pós-Graduação em Estudos Linguísticos. Belo Horizonte, 2007.

SOARES, M. F. Diários escolares reflexivos como narrativas de experiência de aprendizagem. Contexturas: ensino crítico de língua inglesa. São Paulo, n 8, p.79-90, 2005. , M. F. Compondo identidades: construindo diários nas aulas de língua inglesa. Tese de doutorado. Pontifícia Universidade Católica de São Paulo. São Paulo, 2006. 210 p.

STAKE, R. E. The art of case study research. Sage Publications, 1995.

TARAS, M. Summative assessment: the missing link for formative Assessment. Journal of Further and Higher Education, 33:1, 57-69. 2009. crossref http://dx.doi.org/10.1080/03098770802638671

YINGER, R.J; CLARK, C. M. Reflexive journal writing: theory and practice. Paper. Michigan: I.R.T Michigan State Uni. East ansing, 1981.

ZABALZA, M. A. Diários de aula: um instrumento de pesquisa e desenvolvimento profissional. Porto Alegre: Artmed, 2004..

Artigo recebido em: 28.02 .2014

Artigo aprovado em: 23.05.2014 